\title{
Maternal Knowledge on Complementary Feeding Practice and Nutritional Status of Children 6-23 Month in Jigjiga Town
}

\author{
Yimer Mihretie* \\ Department of Food Science and Nutrition, Jigjiga University, Ethiopia
}

*Corresponding author: Yimer Mihretie, Department of Food Science and Nutrition, Collage of Dry land Agriculture, Jigjiga University, Ethiopia.

Received Date: August 09, 2018

Published Date: August 29, 2018

\begin{abstract}
The purpose of this study was to determine mothers knowledge on complementary feeding practices and relate this to the nutritional status of their children aged 6-23 months. The study adopted a cross-sectional analytical study design and was carried out at the kebele 05 in Jigjiga town among the randomly sampled 110 mothers and their children. A researcher-administered questionnaire was used to collect data. Data was entered and analyzed using SPSS version 20 ENA [1]. Anthropometric measurements were analyzed using Microsoft Excel. The respondents were mostly young (mean age $27.7 \pm 4.7$ years), married ( $87.3 \%$ ), housewives $(70 \%)$ with mainly primary school level of education $(48.2 \%)$. The main sources of income for most households were business (48.6\%) and casual labor (31.8\%). Mothers had high knowledge on complementary feeding practice (90\%) out of the 20 knowledge questions. All (100\%) the children aged 6-8 had been introduced to solids, semi-solids and soft foods. Majority of the breast-fed children received minimum meal frequency were 6-8 months old (86.7\%) and 9-23 months old (90\%) unlike the non-breast fed children (80\%). Overall, $52.7 \%$ of all the children were stunted, $49.1 \%$ wasted and $43.6 \%$ underweight. Maternal knowledge on complementary feeding was significantly associated with nutritional status of their children. Mothers knowledge on feeding the sick and recovering children was related to underweight in children. The same was true of mothers who knew that a child's main meal should be diversified. Mothers knowledge on complementary feeding practices was not significantly related to her complementary feeding practices $(p>0.05)$. Nutrition programme should pay attention to cultural beliefs on infant and young child feeding.
\end{abstract}

Keywords: Anthropometric measurements; Complementary feeding; Mothers knowledge, Nutrition program

\section{Introduction}

\section{Background to the study}

Infant feeding practices play a main role in determining optimal development of infants. Poor breast feeding and infant feeding practices have adverse consequences for the health and nutritional status of children, which in turn has adverse consequences on the mental and physical development WHO [2].The period from birth to 2 years of age is a "critical window" for the promotion of optimal growth, health and cognitive development [3]. Early years have been recognized as time for developing good dietary habits and important time for taking in nutrients for optimal growth and development $[4,5]$. Poor breastfeeding patterns, low nutrient density and poor quality of complementary feeds accounts for nutrient deficiency, illness and infections in children leading to malnutrition at an early age $[3,6]$. Malnutrition has a profound effect on a child's growth and development, as it can lead to permanent stunting, impaired brain and mortar development or excess weight gain, predisposing the child to obesity later in life [7,8]. Infant and young child feeding practices directly affect the nutritional status of children under two years, impacting on child survival [9,10,]. World Health Organization (WHO) [11] recommends exclusive breastfeeding for the first 6 months, introduction of complementary feeding with continued breastfeeding for at least 2 years. Similarly, WHO [2] recommended infant and young child feeding practices for children aged 6-23 months include: continued breastfeeding; feeding semisolid/solid food according to the age of the child; and feeding a variety of foods such as cereals, fruits, vegetables. Breastfeeding of up to 2 years of age and beyond is an important source of nutrients, fluids and immunological protection, while appropriate complementary food promotes good health, nutritional status and 
growth of young children WHO [11]. In many developing countries, complementary feeding is introduced too early and the quality and quantity of the foods are insufficient, thus children are at the risk of nutritional deficiency $[12,13]$. Most of the complementary foods are cereal-based gruels low in energy and nutrient density and more so inadequate in iron, zinc, pyridoxine, riboflavin, niacin, calcium, thiamine, foliate, ascorbic acid and vitamin A [14]. Malnutrition has been responsible directly or indirectly for $60 \%$ of the 10.9 million deaths annually among children under 5 years in the whole world, where two thirds of these deaths are associated with inappropriate feeding practices in the first year of life $[15,16]$. In developing countries, malnutrition accounts for $50 \%$ deaths of the children under five years [17].

In Africa, malnutrition contributes to half of the 9.7 million annual under five deaths and is a leading cause of diseases and disabilities in children [18,19]. In Kenya, inappropriate complementary feeding practices contribute to more than 10000 annual deaths for children under five years [20]. Malnutrition rates for the under-fives in 2008 were, $7 \%$ wasted, $35 \%$ stunted and $16 \%$ underweight based on the Kenya Demographic [21]. To reduce child mortality and achieve the fourth Millennium Development Goal i.e., to reduce child mortality rates [22], there is need to improve the feeding practices of the children, since child feeding is one of the most neglected determinants of young child nutrition in spite of the importance in growth pattern of the child hence the need for this study.

Many observational studies show that maternal knowledge of optimal child feeding practices like exclusive breastfeeding for six months, continued breastfeeding and the timely transition to adequate complementary food is basic to keep health of a child [23]. Knowledge does not necessarily translate to practice as supported by Sellen DW [24], who observed that a combination of mothers self-perception, assessment of infant's wellbeing, culture; food availability and financial status influence the actual complementary feeding, hence child nutritional status. In Jigjiga, Somali region of Ethiopia, mothers knowledge on complementary feeding has been identified as a major gap in complementary feeding which needs to be addressed hence the need for this study. Therefore, this study was aimed at to determine mothers' knowledge on complementary feeding practices and the nutritional status of their children aged 6-23 months in Jigjiga town.

\section{Methodology}

\section{Study area}

The study was conducted in Jigjiga town, ESRS, eastern Ethiopia. The ESRS is the second largest among the nine regional states of Ethiopia, with a land area of $375,000 \mathrm{~km}^{2}$ and an estimated population of five million people. An estimated $85 \%$ of regional populations earn their livelihoods from pastoralism or agropastoralism. Jigjiga, the capital city of ESRS, is located in Fafan zone. It is located $632 \mathrm{~km}$ east of Addis Ababa and $60 \mathrm{~km}$ west of border with Somalia. The city has an elevation of 1.609 meters above the sea level. The climate of Jigjiga is semi-arid (koppen climate) with the influence of mountain climate with hot and dry summers and cold winters. This is attributed to the fact that Jigjiga is located on a plain surrounded by mountains and to its distance to the sea and its effects. It was estimated that 348,421 people live in Jigjiga Woreda of which about $15.3 \%$ are children under five years of age and $23.1 \%$ are women in the reproductive age group [25]. According to the annual report of Jigjiga council health office [26], there is one newly constructed referral hospital, one general hospital, six health centers and 28 health posts in the Woreda. In Jigjiga Woreda, there are four ethnic groups (Somali, Oromo, Amhara and Guragae) the Somali ethnic group is the most predominant (99.0\%) the rest are Oromo (0.44\%), Guragae (0.30\%) and the Amhara (0.25\%) [25].

\section{Research design}

The study was conducted from October to June 2018. A crosssectional analytical design was used in this study. This is because a cross-sectional research gives an overview of what is going on with the variable of interest. In this regard, the two variables: dependent and independent variables were included. The dependent variables are complementary feeding and child's nutritional status (wasting, stunting and underweight), whereas the independent variables are maternal knowledge on complementary feeding and complementary feeding practices. This study provided information on mothers knowledge on complementary feeding and showed the association between mothers knowledge and practices on complementary feeding and the nutritional status of their children.

\section{Target population and sample size}

The target population was mothers and their children aged 6-23 months living in the selected three zones of 05 kebele in Jigjiga town. The sample size was calculated using Yamane, Taro, [27] formula for an estimated population of 1000 mothers and respective children.

$$
n=\frac{N}{1+N e^{2}}
$$

Where:

1. $n=$ Total sample size which will be included in this study.

2. $\mathrm{N}=$ Number of total population

3. $\mathrm{e}=\mathrm{is}$ the level of precision (0.05).

So the above expression becomes

$$
\mathrm{n}=\frac{1000}{1+1000 * 0.05^{2}}
$$

$\mathrm{n}=286$

\section{Correction factor}

$$
\mathrm{NC}=\left[\frac{n}{1+(n-1) \div N}\right]
$$

$\mathrm{NC}=$

Where NC $=$ corrected sample size

1. $\mathrm{n}=$ Initial sample size

2. $\mathrm{N}=$ the estimated total population size is $=180$, therefore:

$$
\left[\frac{286}{1+(286-1) \div 180}\right]
$$

$\mathrm{NC}=110$ 


\section{Sampling technique}

In this study multi-stage sampling method was used, By considering Jigjiga town, which consist of one kebele (a district where there are 10 zones, and a zone contains 1000 household together) [26], three zones were selected from these ten zones by simple random sampling, then the calculated sample size (110) was proportionally allocated according to household population load of each zone, a systematic sampling technique was used to identify the study households from each zones. In this method when there was no eligible person in the selected household, the next door was visited. Therefore, the study has contained inclusive and exclusive parameters. Only mothers of children aged 6-23 months, attending Jigjiga hospital and willing to participate were considered in the study as inclusive, while Mothers whose children were physically deformed, mentally or chronically ill children based on maternal self-reports and information of the health card were excluded from the study as it would affect their anthropometric measurements. (Figure 1).

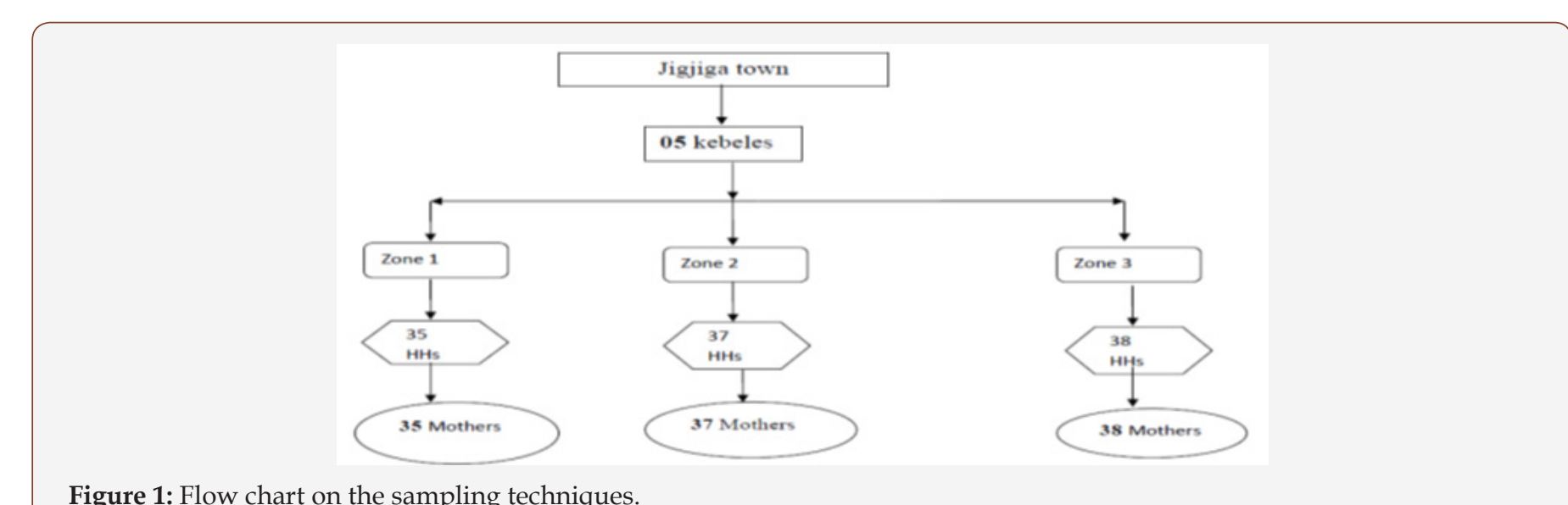

Figure 1: Flow chart on the sampling techniques.

\section{Method of data collection and instrument}

The structured questionnaire was administered to the sampled mothers, fathers and their children aged 6-23 months living in Jigjiga town. It included information on; socio-economic and demographic characteristics, complementary feeding practices, mother's knowledge on complementary feeding practices and child's anthropometric measurements. Information on the above was collected using researcher-administered questionnaire. The questionnaires where first prepared in English language and then translated to local language Somali which they can understand. Focus Group Discussion was conducted by preparing important discussion points.

\section{Anthropometric measurements}

The weight of the child was measured in kilograms at 10grams accuracy. The child was in minimal clothing. Two weights were taken by the research assistants and recorded and, in cases of large variances the measurements were repeated until an acceptance variance was obtained. A UNICEF Salter Scale Model 2356 S Seca, [28] was used to measure the weight of the children. Since this study was carried out in a Jigjiga hospital, all the children had child health cards from where the children's age was recorded. The length of the child was measured in centimeters using a pediatric height board of standard design (SECA) [28] with 0.1 Centimeter accuracy. Children were measured while lying on their back on the 25 length board. The length measurement was taken twice and an average of the two computed. In cases of large variances, the measurements were repeated until an acceptance variance was obtained.

\section{Pre-testing of data collection tools}

The structured questionnaire was pre-tested on mothers who have children 6-23 months in the selected kebele, based on the findings of the pre-test necessary comments made to the questionnaire prior to the actual survey.

\section{Validity}

Content validity was established in the structured questionnaire using the indicators for the assessment of Infant and Young Child Feeding Practices [29] and the guiding principles for complementary feeding for a breastfed child [30]. The questionnaire was presented to experts in nutrition from Jigjiga University in the department of Food science and Nutrition to establish content validity.

\section{Data analysis and Interpretation}

Raw data was cleaned, coded and entered into the computer using Microsoft Excel 2013 and Software for Emergency Nutrition Assessment for Standardized Monitoring and Assessment of Relief and Transitions (ENA for SMART) [31]. Socio-economic and demographic characteristics, maternal knowledge and practices on complementary feeding were analyzed using Microsoft Excel. The child nutritional status was analyzed using ENA for SMART and interpreted using the Z- Score (WHO, 2006a). Children with a Z-score of below -2SD for WFA, WFH and HFA were considered underweight, wasted and stunted respectively. Children below -3SD for WFA, WFH and HFA were considered severely malnourished. Children between -2SD and -3SD for the above indices were considered moderately malnourished. Those above -2SD were considered normal or well-nourished children (WHO, 2006a).

\section{Ethical consideration}

In order to proceed the data collection process official ethical clearance letter was taken from Jigjiga University Department of Food science and Nutrition. In the letter, the objective and benefits of the study was explained in detail to the respondents. Respondents were interviewed only after they agreed and signed the consent.

\section{Result}

\section{Demographic characteristics of the children}

Both sexes were almost equally represented with $48.1 \%$ being 
males and $51.8 \%$ females. The majority of the children were in the age range of 6-12 months (77.3\%) with an average age of 10 months (Table 1).

Table 1: Demographic characteristics of the children.

\begin{tabular}{|c|c|c|}
\hline $\begin{array}{c}\text { Children's Demographic } \\
\text { Characteristics }\end{array}$ & $\mathbf{N = 1 1 0}$ & \\
\hline Sex of the Child & $\mathbf{N}$ & $\%$ \\
\hline Male & 53 & 48.1 \\
\hline Female & 57 & 51.8 \\
\hline Age of the Children (Months) & & \\
\hline 6-12months & 85 & 77.3 \\
\hline 13-23months & 25 & 22.7 \\
\hline
\end{tabular}

Demographic and socio-economic characteristics of the mothers

In this study the youngest mother was 17 years while the oldest was 48 years with the mean age for all mothers being 27.7 years. Many $(87.3 \%)$ of the mothers were married with the rest (10.9\%) being either single or separated. On the whole, mothers had low level of education; over one percent (4.55\%) had never gone to school while only $1.8 \%$ had reached the university; a notable proportion had primary school level of education (48.2\%), secondary school level of education $(34.55 \%)$ and college $(10.2 \%)$. The mothers economic status was low as more than half $(70 \%)$ of them were housewives, $18.2 \%$ were engaged in petty trade and domestic workers, only $10 \%$ were in waged labor while $1.8 \%$ were unemployed and students (Table 2).

Table 2: Maternal demographic and socio-economic characteristics.

\begin{tabular}{|c|c|c|}
\hline Mothers Demographic and Socio-Economic Characteristics & $\mathrm{N}=\mathbf{1 1 0}$ & \\
\hline & $\mathbf{N}$ & $\%$ \\
\hline \multicolumn{3}{|l|}{ Maternal age (years) } \\
\hline $17-20$ & 10 & 9.1 \\
\hline $21-30$ & 80 & 72.7 \\
\hline $31-48$ & 20 & 18.2 \\
\hline \multicolumn{3}{|l|}{ Marital Status } \\
\hline Married & 96 & 87.3 \\
\hline Single & 12 & 10.9 \\
\hline Separated & 2 & 1.8 \\
\hline \multicolumn{3}{|l|}{ Mothers Education Level } \\
\hline No education & 5 & 4.55 \\
\hline Primary School & 53 & 48.2 \\
\hline Secondary School & 38 & 34.55 \\
\hline College & 12 & 10.2 \\
\hline University Degree & 2 & 1.8 \\
\hline \multicolumn{3}{|l|}{ Mother's Religion } \\
\hline Muslim & 99 & 90 \\
\hline Protestant & 5 & 4.5 \\
\hline Catholic & 6 & 5.5 \\
\hline None & 0 & 0 \\
\hline \multicolumn{3}{|l|}{ Mothers Main Occupation } \\
\hline Waged labor & 11 & 10 \\
\hline Pretty trade/ domestic help & 20 & 18.2 \\
\hline Unemployed/student & 2 & 1.8 \\
\hline Housewife & 77 & 70 \\
\hline
\end{tabular}

Demographic and socio-economic characteristics of the husbands

The result has shown that almost half (50.9\%) of the husbands of the study participants (mothers) had secondary education while the others had primary education (20.9\%) and college $(25.5 \%)$. The major occupation for the husbands was either petty trade $(43.6 \%)$ or casual labor (35.5\%). The rest of the husbands were salaried laborers, unemployed and farmers; (18.2\%), (1.8\%) and $(0.9 \%)$ respectively (Table 3$)$.

Table 3: Husbands demographic and socio-economic characteristics.

\begin{tabular}{|c|c|c|}
\hline Husbands Demographic and Socio-economic Characteristics & N=110 & N \\
\hline Husbands Education & & \\
\hline Primary School & 23 & 20.9 \\
\hline Secondary School & 56 & 50.9 \\
\hline
\end{tabular}




\begin{tabular}{|c|c|c|}
\hline College & 28 & 25.5 \\
\hline University & 3 & 2.73 \\
\hline Husbands' Main Occupation & & \\
\hline Agricultural labor & 1 & 0.91 \\
\hline Waged labor (salaried) & 20 & 18.2 \\
\hline Waged labor (casual) & 39 & 35.5 \\
\hline Petty trade & 48 & 43.6 \\
\hline Unemployed & 2 & 1.8 \\
\hline
\end{tabular}

\section{Socio-economic profiles of the households}

The major source of income for most households was own businesses (48.6\%), followed by causal work (31.8\%), salaried employment (15.3\%), support by their parents $(2.1 \%)$, farmers $(1.7 \%)$ or relied on financial savings $(1.0 \%)$ and charity organizations (1.4\%) as shown (Figure 2).

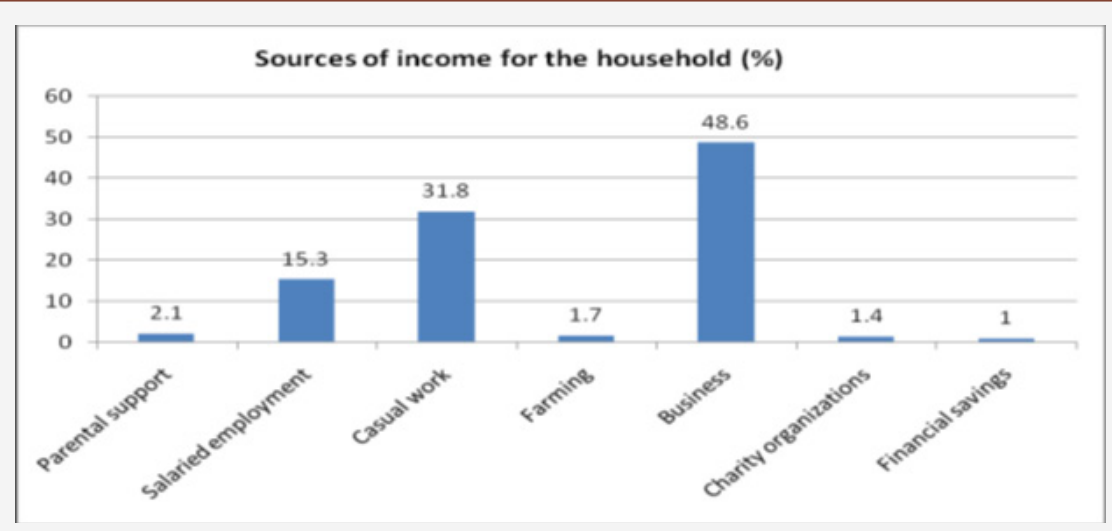

Figure 2: Socio-economic profile of the households

\section{Household income and expenditure}

(Table 4)

Table 4: Household income and expenditure.

\begin{tabular}{|c|c|c|}
\hline $\begin{array}{l}\text { Household } \\
\text { Expenditure }\end{array}$ & $N=110$ & \\
\hline & $\begin{array}{l}\text { Mean expenditure } \\
\text { (birr) }\end{array}$ & $\begin{array}{l}\text { Standard deviation } \\
\text { (SD) }\end{array}$ \\
\hline $\begin{array}{l}\text { Average monthly } \\
\text { income }\end{array}$ & 3750 & $\pm 12,580$ \\
\hline $\begin{array}{l}\text { Monthly expenditure } \\
\text { on rent }\end{array}$ & 6250 & $\pm 1,738$ \\
\hline $\begin{array}{l}\text { Daily expenditure on } \\
\text { food }\end{array}$ & 700 & \pm 94 \\
\hline $\begin{array}{l}\text { Monthly expenditure } \\
\text { on education }\end{array}$ & 1600 & \pm 1230 \\
\hline $\begin{array}{l}\text { Monthly expenditure } \\
\text { on health }\end{array}$ & 1150 & \pm 535 \\
\hline $\begin{array}{c}\text { Monthly expenses } \\
\text { on airtime, clothing, } \\
\text { leisure, investments } \\
\text { and support to other } \\
\text { relatives }\end{array}$ & 2650 & \pm 1440 \\
\hline
\end{tabular}

\section{Mothers knowledge on complementary feeding practices}

In this study, knowledge questions were based on the guiding principles of complementary feeding for a breast fed child PAHO/ WHO [15]. The study showed most (36.4\%) of the mothers had high knowledge on exclusive breastfeeding for the first 6 months and $31.8 \%$ of the mothers reported that infants and children should be breastfed for two years and beyond (Table 5). Majority of mothers $(90 \%)$ indicated that children should be introduced to complementary feeding at 6 months. Less number (27.3\%) of the mothers were aware that adding ghee or oil enriches children's porridge nutritionally, while $54.5 \%$ of the mothers thought that children who had one year old should be breastfed two times a day, in the morning and evening. (36.4\%) of the mothers knew that at 6 months children should be introduced to complementary foods that are sieved and/or pureed for optimal intakes. Over half (63.6\%) of the mothers reported that by one year children can be fed from the family pot. Majority of the mothers had high knowledge on hygiene practices; washing hands before preparing food for a child (44.5\%) and treating of water used for preparing foods and drinks for the child (46.4\%). The highest percentage (90.9\%) of the mothers thought bottle feeding was a better option for feeding non-breastfed children. Half of the mothers (50\%) indicated that sick children and those recovering from illness should not be fed on diluted porridge or fruit juices. Less than half of the mothers reported the need for responsive feeding of complementary foods to ensure optimal intakes were $45.5 \%$ thought, the mother should be the primary feeder of her child, while $54.5 \%$ stated that the mother should assist her child to eat up to the age of 2 years. Majority (81.8\%) of the mothers indicated that 1-2 table spoonful of food are enough meal for one year child. On the whole, (31.8\%) of the mothers knew that children's meals should be balanced, while only $18.2 \%$ stated that breast milk is still adequate in proteins even after 6 months. More percentage of the mothers $(40.9 \%)$ knew that fruits and vegetable should form part of a child's diet during complementary feeding. Low knowledge level was indicated on flour mixtures of legumes and cereals as $9.1 \%$ reported that flour mixtures of lentils, millet, sorghum, maize, beans and silver fish (omena) are not nutritious flours for child's porridge (Table 5). 
Table 5: Maternal knowledge on Breastfeeding and complementary feeding.

\begin{tabular}{|c|c|c|}
\hline Aspects of knowledge on complementary feeding & $\mathrm{N}=\mathbf{1 1 0}$ & \\
\hline & $\mathbf{N}$ & $\%$ \\
\hline \multicolumn{3}{|l|}{ Breastfeeding: } \\
\hline Infants exclusively breastfeed for the 1 st 6 months of life & 40 & 36.4 \\
\hline A child should be breastfed on demand & 35 & 31.8 \\
\hline Continue breastfeeding for 2 years and beyond & 35 & 31.8 \\
\hline \multicolumn{3}{|l|}{ Complementary feeding (CF) practices: } \\
\hline CF should be introduced at 6 months & 99 & 90 \\
\hline \multicolumn{3}{|l|}{ Meal frequency and energy density of CF: } \\
\hline Feed a breastfed 12 months child two times a day & 60 & 54.5 \\
\hline Feed a child based on hunger cues & 20 & 18.2 \\
\hline Ghee or oil enrich child's porridge & 30 & 27.3 \\
\hline \multicolumn{3}{|l|}{ Consistency of CF: } \\
\hline Feed a 6 months old child on pureed / sieved foods & 40 & 36.4 \\
\hline Children should eat from the family pot from 1 year & 70 & 63.6 \\
\hline \multicolumn{3}{|l|}{ Safe preparation and storage of CF: } \\
\hline Hands should be washed before preparing children's food & 49 & 44.5 \\
\hline Feeding bottles are not appropriate for feeding non-breastfed children & 10 & 9.1 \\
\hline Water for preparing food and drinks for children should be treated & 51 & 46.4 \\
\hline \multicolumn{3}{|l|}{ Feeding during illness: } \\
\hline Do not fed sick /recovering child on dilute porridge / fruit juices & 55 & 50 \\
\hline \multicolumn{3}{|l|}{ Responsive feeding: } \\
\hline Mother should assist a child to eat until 2 years & 60 & 54.5 \\
\hline A mother should be the primary feeder of the child & 50 & 45.5 \\
\hline \multicolumn{3}{|l|}{ Amount of CF: } \\
\hline 1-2 table spoonful of food is adequate meal for a one-year old child & 90 & 81.8 \\
\hline \multicolumn{3}{|l|}{ Nutrient content of CF: } \\
\hline $\begin{array}{l}\text { Flour mixtures of ndengu/millet/ sorghum/maize/ beans and omena are not best for child's } \\
\text { porridge: }\end{array}$ & 10 & 9.1 \\
\hline Fruits and vegetables are complementary foods & 45 & 40.9 \\
\hline Breast milk is adequate in proteins even after 6 months & 20 & 18.2 \\
\hline A child's main meal should be balanced & 35 & 31.8 \\
\hline
\end{tabular}

\section{Breastfeeding practices}

Since complementary feeding is a period during which other foods or liquid are provided along with breast milk as defined by WHO, breastfeeding was considered important. Less percentage $(18.2 \%)$ of the children in the study had been breast fed but at the time of the study it had increased to $81.8 \%$ (Table 6).

Table 6: Breastfeeding practices.

\begin{tabular}{|c|c|c|}
\hline Breastfeeding practices & $\mathbf{N = 1 1 0}$ & \\
\hline & $\mathbf{N}$ & $\%$ \\
\hline Ever breastfed & 20 & 18.2 \\
\hline Still breastfeeding & 90 & 81.8 \\
\hline
\end{tabular}

\section{Complementary feeding practices}

Introduction of solids, semi-solids and soft foods: Introduction of solids, semi-solids and soft foods to children at 6-8 months is an indicator of infant and young child feeding practices and an important aspect in complementary feeding. The proportion of breastfed infants 6-8 months of age who received solid, semisolid or soft foods indicate timely introduction of complementary feeding WHO [29]. Based on a 24-hour recall, $100 \%$ of the children, 6-8 months old had received solid or semi-solid foods although $21.6 \%$ had been complemented earlier (before 6 months), while a few of the children $(0.3 \%)$ had not started feeding by 9 months as shown in (Figure 3). 


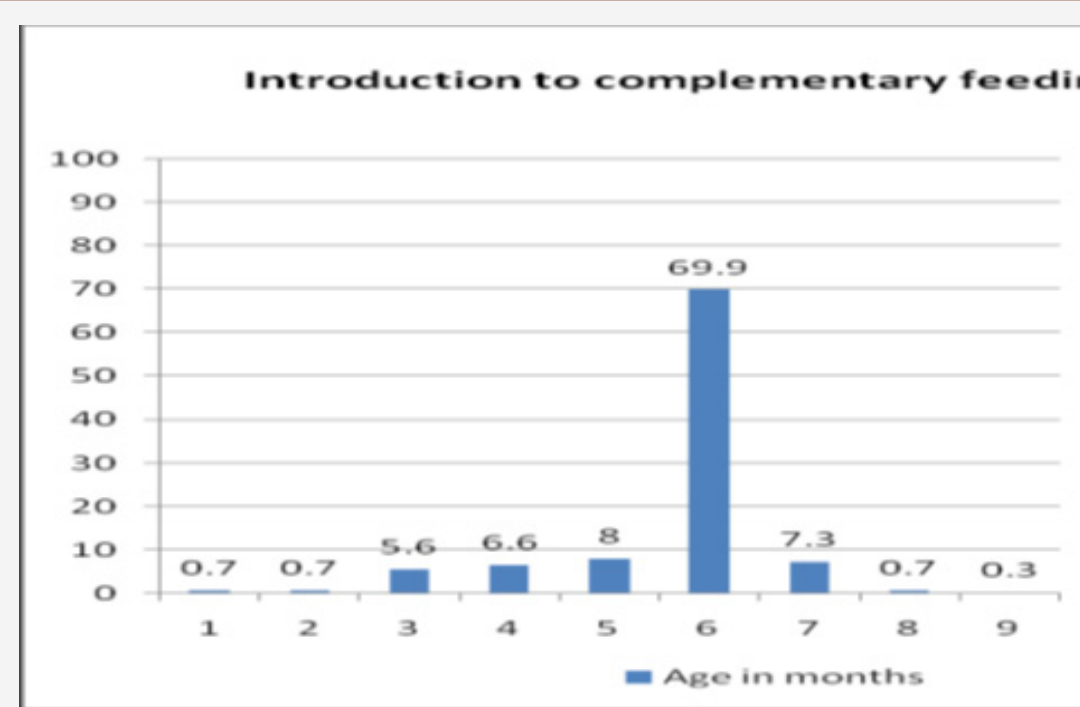

Figure 3: Introduction to complementary.

\section{Minimum meal frequency}

(Table 7)

Table 7: Minimum meal frequency.

\begin{tabular}{|c|c|c|c|}
\hline Age in months & $\mathbf{N = 1 1 0}$ & \\
\hline & Frequency of feeding & $\mathbf{N}$ & $\%$ \\
\hline Breastfed children (N=90) & & & \\
\hline 6-8months (n=30) & $\geq 2$ times & 26 & 86.7 \\
\hline 9-23 months ( $=60$ ) & <2times & 4 & 13.3 \\
\hline & <3times & 54 & 90 \\
\hline $\begin{array}{c}\text { Non breast-fed children } \\
(\mathbf{n}=\mathbf{2 0})\end{array}$ & $\geq 4$ times & 6 & 10 \\
\hline 6-23months(n=20) & $<4$ times & 4 & 20 \\
\hline
\end{tabular}

\section{Consumption of iron-rich foods and vitamin-a rich fruits and vegetables}

(Table 8)

Table 8: Consumption of vitamin A rich foods and iron rich foods.

\begin{tabular}{|c|c|c|}
\hline Children aged 6-23 months & N=110 & \\
\hline & $\begin{array}{c}\text { Vitamin A-rich } \\
\text { Foods }\end{array}$ & $\begin{array}{c}\text { Iron-rich } \\
\text { foods }\end{array}$ \\
\hline n (\%) & $\mathbf{n}$ (\%) \\
\hline Children 6-23 months (110) & & \\
\hline Consumed & $70(63.6)$ & $33(30)$ \\
\hline Not consumed & $40(36.4)$ & $77(70)$ \\
\hline Children 6-11months (n=73) & & \\
\hline Consumed & $48(65.8)$ & $16(21.9)$ \\
\hline Not consumed & $25(34.2)$ & $57(78.1)$ \\
\hline Children 12-17 months (n=25) & & \\
\hline Consumed & $13(52)$ & $14(56)$ \\
\hline Not consumed & $12(48)$ & $11(44)$ \\
\hline Children 18-23 months (n=12) & & \\
\hline Consumed & $8(66.7)$ & $3(25)$ \\
\hline Not consumed & $4(33.3)$ & $9(75)$ \\
\hline
\end{tabular}

\section{Minimum dietary diversity}

The consumption of a varied diet suggests a possibility of a child to having taken a balanced diet which is an important aspect in the child's nutritional status. Minimum dietary diversity was established based on the number of food groups the index child consumed in the previous 24 hours prior to the data collection. Seven food groups as recommended internationally by WHO [29] were considered in the study. The food groups were: grains, roots and tubers; legumes and nuts; dairy products; meat and animal products; eggs; vitamin A rich fruits and vegetables and other fruits and vegetables. Majority of the children (95.5\%) had eaten food prepared from grains, tubers and roots. The intakes of vitamin A rich fruits and vegetables were $60.8 \%$, iron rich foods intakes (flesh meats) was $11.5 \%$ while the consumption of other fruits was relatively higher $(71.4 \%)$. Consumption of proteins was highest from dairy products (83.2\%), and lower in legumes (28\%) and least for flesh meats and eggs (11.5\%) and (2.4\%) respectively (Figure 4) \& (Table 9).

Table 9: Dietary Diversity Score for Complementary Feeding.

\begin{tabular}{|c|c|c|}
\hline $\begin{array}{c}\text { Dietary diversity score (children 6-23 } \\
\text { months) }\end{array}$ & $\mathrm{N}=110$ & \\
\hline & $\mathbf{N}$ & $\%$ \\
\hline \multicolumn{3}{|l|}{ Children 6-23 months $(\mathrm{n}=110)$} \\
\hline$<4$ food groups & 30 & 27.3 \\
\hline$\geq 4$ food groups & 80 & 72.7 \\
\hline \multicolumn{3}{|l|}{ Children 6-11 months $(n=73)$} \\
\hline$<4$ food groups & 24 & 32.9 \\
\hline$\geq 4$ food groups & 49 & 67.1 \\
\hline \multicolumn{3}{|l|}{ Children 12-17 months $(n=25)$} \\
\hline$<4$ food groups & 10 & 40 \\
\hline$\geq 4$ food groups & 15 & 60 \\
\hline \multicolumn{3}{|l|}{ Children 18-23 months $(n=12)$} \\
\hline$<4$ food groups & 4 & 33.3 \\
\hline$\geq 4$ food groups & 8 & 66.7 \\
\hline
\end{tabular}




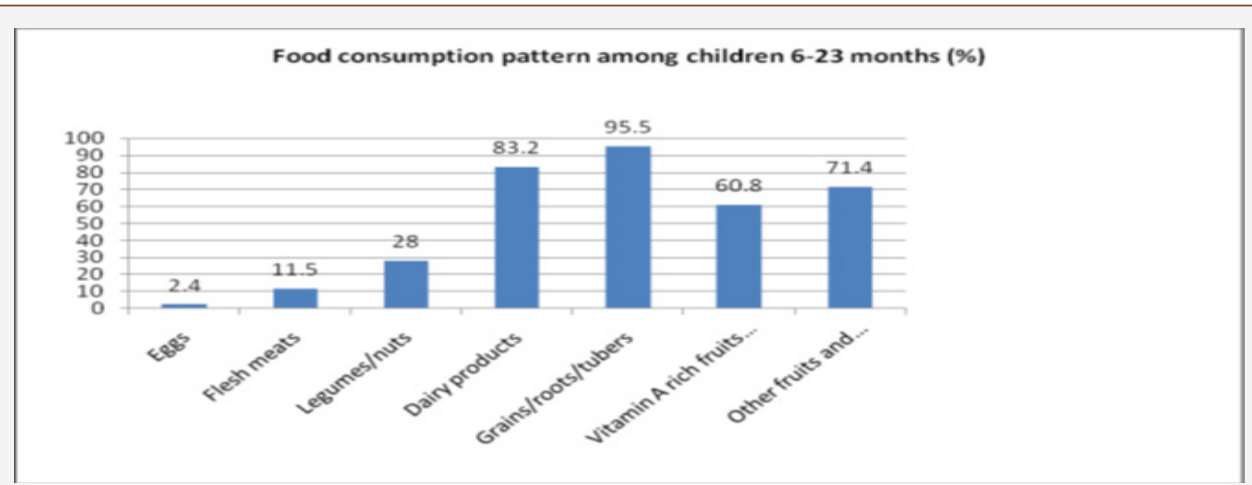

Figure 4: Food consumption among children 6-23 months.

\section{Maternal hygiene practices}

(Table 10)

Table 10: Maternal hygiene practices.

\begin{tabular}{|c|c|c|}
\hline Hygiene practices & $\mathbf{N = 1 1 0}$ & \\
\hline Treatment of drinking water (n=65) & N & \% \\
\hline Washing hands (n=30) & & 89.2 \\
\hline Before food preparation & 4 & 13.3 \\
\hline Before eating & 3 & 10 \\
\hline Before feeding children & 5 & 16.7 \\
\hline After defecation & 6 & 20 \\
\hline After returning from outside the house & 7 & 23.3 \\
\hline After handling garbage & 5 & 16.7 \\
\hline Use of soap to wash hands (n=15) & 15 & 50 \\
\hline
\end{tabular}

Nutritional status of the children

Stunting (Height-for-Age) based on Z Scores: Height-for-Age index is an indicator of linear growth retardation and cumulative growth deficits. Children who are below the -2SD or - 2 Z-scores are considered short for their age (stunted) and are chronically malnourished, while children who are below -3SD of the Z-scores are considered severely stunted WHO [32]. Stunting reflects failure to receive adequate nutrition over a long period of time and is also affected by recurrent chronic illness. In this study, 52.7\% (9.8- 17.7, $95 \% \mathrm{CI}$ ) of all the children were stunted with less boys $50.9 \%(12.9$ - 25.6, 95\% C.I.) than girls $55.9 \%$ (4.8 - 13.9, 95\% C.I.) stunted. About 30.9\% (5.7-12.2, 95\% C.I.) were moderately stunted, while $16.4 \%$ (2.9-8.0, 95\% C.I.) were severely stunted (Table 11).

Table 11: Prevalence of stunting by sex based on Z-scores.

\begin{tabular}{|c|c|c|c|}
\hline Prevalence & 110) & Boys $(n=51)$ & Girls $(n=59)$ \\
\hline $\begin{array}{c}\text { Stunting } \\
(<-2 \text { z-score })\end{array}$ & $\begin{array}{c}\text { (58) } 52.7 \% \\
(9.8-17.7,95 \% \\
\text { C.I. })\end{array}$ & $\begin{array}{c}\text { (26) } 50.9 \% \\
(12.9 \text { - 25.6, } \\
95 \% \text { C.I. })\end{array}$ & $\begin{array}{c}\text { (33) } 55.9 \% \\
(4.8-13.9,95 \% \\
\text { C.I. })\end{array}$ \\
\hline $\begin{array}{c}\text { Moderate } \\
\text { stunting } \\
(<-2 \text { z-score and } \\
>=-3 \text { z-score })\end{array}$ & $\begin{array}{c}\text { (34) } 30.9 \% \\
(5.7-12.2,95 \% \\
\text { C.I. })\end{array}$ & $\begin{array}{c}\text { (16) } 11.3 \% \\
\text { (7.1 - 17.6, } 95 \% \\
\text { C.I.) }\end{array}$ & $\begin{array}{c}\text { (17) } 28.8 \% \\
(2.8-10.5,95 \% \\
\text { C.I. })\end{array}$ \\
\hline $\begin{array}{l}\text { Severe stunting } \\
\text { (<-3 z-score) }\end{array}$ & $\begin{array}{c}\text { (18) } 16.4 \% \\
(2.9-8.0,95 \% \\
\text { C.I. })\end{array}$ & $\begin{array}{c}\text { (9) } 7.1 \% \\
\text { (3.9 - } 12.6,95 \% \\
\text { C.I.) }\end{array}$ & $\begin{array}{c}\text { (9) } 15.3 \% \\
(1.1-6.9,95 \% \\
\text { C.I. })\end{array}$ \\
\hline
\end{tabular}

Wasting (weight-for-height) based on $\mathrm{Z}$ scores: Wasting describes the current or short-term nutritional status due to inadequate dietary intake or recent episodes of illness causing loss of weight and the onset of malnutrition. Wasting is also referred to as acute malnutrition. Children whose weight- for- height is below -2SD or -2 Z-score are considered thin or wasted and are acutely malnourished while children whose weight-for-height is below -3 SD or below -3 Z-score are considered Severely wasted [32]. The Somali region wasting rate in this study was $49.1 \%$ (8.6-16.2, 95\% C.I.) with less in boys $47.1 \%$ (11.7-24.1, 95\% C.I.) than girls $50.8 \%$ (3.8-12.2, 95\% C.I.) wasted. About 34.5\% (6.9-13.8, 95\% C.I.), were moderately wasted and $16.4 \%(1.0-4.5,95 \%$ C.I) were severely wasted (Table 12).

Table 12: Prevalence of acute malnutrition by sex- based on Z-scores and/or edema.

\begin{tabular}{|c|c|c|c|}
\hline Prevalence & All (n=110) & Boys (n= 51) & Girls (n= 59) \\
\hline $\begin{array}{c}\text { Somali region } \\
\text { malnutrition } \\
(<-2 \text { z-score })\end{array}$ & $\begin{array}{c}(54) 49.1 \% \\
(8.6-16.2,95 \% \\
\text { C.I. })\end{array}$ & $\begin{array}{c}(24) 47.1 \% \\
(11.7-24.1, \\
95 \% \text { C.I. })\end{array}$ & $\begin{array}{c}(30) 50.8 \% \\
(3.8-12.2,95 \% \\
\text { C.I. })\end{array}$ \\
\hline $\begin{array}{c}\text { Moderate } \\
\text { malnutrition } \\
(<-2 \text { z-score and } \\
>=-3 \text { z-score })\end{array}$ & $\begin{array}{c}(38) 34.5 \% \\
(6.9-13.8,95 \%\end{array}$ & $\begin{array}{c}(19) 37.3 \% \\
(8.8-20.1,95 \% \\
\text { C.I. })\end{array}$ & $\begin{array}{c}(18) 30.3 \% \\
(3.3-11.4,95 \%\end{array}$ \\
\hline $\begin{array}{c}\text { Severe stunting }) \\
(<-3 \text { z-score })\end{array}$ & $\begin{array}{c}(18) 16.4 \% \\
(1.0-4.5,95 \%\end{array}$ & $\begin{array}{c}(8) 15.7 \% \\
(1.5-8.0,95 \%\end{array}$ & $\begin{array}{c}(11) 18.6 \% \\
(0.1-3.8,95 \%\end{array}$ \\
\hline
\end{tabular}

Underweight (weight-for-age) based on Z-scores: Weight for age is a composite index of height- for-age and weight- forheight. It takes into account both acute and chronic malnutrition. Children whose weight for age are below-2SD or below $-2 \mathrm{Z}$ scores are considered underweight while children who are below -3SD of the Z-score are considered severely underweight. In this study 43.6 $\%$ (12.9-21.5 95\% C.I.) of the children were underweight, whereas more percentages of boys $49.0 \%$ (15.9-29.5 95\% C.I.) than girls $42.4 \%$ (7.5-18.0 95\% C.I) were underweight. On the whole, $38.2 \%$ (9.8-17.7 95\% C.I.) of all the children were moderately underweight while $18.2 \%$ (1.9-6.3 95\% C.I.) were severely underweight (Table 13).

Table 13: Prevalence of underweight based on weight-for-age Z-scores by sex.

\begin{tabular}{|c|c|c|c|}
\hline Prevalence & All (n=110) & Boys (n= 51) & Girls (n= 59) \\
\hline Underweight & $\begin{array}{c}(48) 43.6 \% \\
(12.9-21.5, \\
(<-2 \text { z-score })\end{array}$ & $\begin{array}{c}(25) 49.0 \% \\
(15.9-29.5,\end{array}$ & $\begin{array}{c}(25) 42.5 \% \\
\text { 95 - } 18.0 .0,95 \%\end{array}$ \\
\hline
\end{tabular}




\begin{tabular}{|c|c|c|c|}
\hline $\begin{array}{c}\text { Moderately } \\
\text { underweight } \\
(<-2 \text { z-score and } \\
>=-3 \text { z-score })\end{array}$ & $\begin{array}{c}\text { (42) } 38.2 \% \\
(9.8-17.7,95 \%\end{array}$ & $\begin{array}{c}\text { (16) } 31.4 \% \\
(11.7-24.1, \\
95 \% \text { C.I. })\end{array}$ & $\begin{array}{c}\text { (24) } 40.7 \% \\
(5.8-15.6,95 \% \\
\text { C.I. })\end{array}$ \\
\hline $\begin{array}{c}\text { Severe } \\
\text { underweight } \\
\text { (<-3 z-score })\end{array}$ & $\begin{array}{c}(20) 18.2 \% \\
(1.9-6.3,95 \%\end{array}$ & $\begin{array}{c}(11) 21.6 \% \\
(2.4-9.9,95 \%\end{array}$ & $\begin{array}{c}\text { (10) } 16.9 \% \\
(0.7-5.9,95 \%\end{array}$ \\
\hline
\end{tabular}

\section{Discussion}

\section{Socio-demographic and economic characteristics of the mothers and children 6-23 months old}

Majority of mothers were young with low levels of education and were housewives. These findings are comparable to those by $[33,34]$ conducted in Jigjiga town. Education is one of the most important resources that enable women to provide appropriate care for their children, which is an important determinant of children's growth and development [35]. Working outside the home is associated with early complementary feeding and cessation of breast feeding [36]. In the present study, low levels of education may have probably contributed to most of the mothers being housewives. A mother who spends most of the time at home with her child may be available to practice optimal feeding practices on her child [37]. The major source of income for most households in this study was business and casual labor. These sources do not attract high income and this was confirmed by mothers during the Focus Group Discussion (FGDs). Mothers reported that the household income was not adequate to provide for food and other necessities. Priority of the household expenditure was therefore placed on house rent first and then food and health services. Being an urban setting, where food is acquired through purchases, the low income level was a major constraining factor to household food security. The low incomes may therefore have contributed to the majority of the household's inability to achieve minimum meal frequency for the non- breastfed and minimum meal dietary diversity consequently minimum acceptable diet for the children.

\section{Complementary Feeding Practices}

Breastfeeding practices: In this study, almost all the children had been breast fed and this compares with the Ethiopian national figures as reported in Ethiopia Demographic Health Survey EDHS $[20,21]$. This was also expected given that culturally Africans breastfeed their children. During complementary feeding, for infants and young children aged 6-23 months old, breastfeeding contributes significantly to the overall nutrient intake, fills most of the energy needs and remains an important source of vitamin A and $\mathrm{C}$, as well as essential fatty acids and can provide to their total energy needs [37].

Timely introduction to solids, semi-solids and soft foods: The mothers introduced complementary feeding foods to their children timely; all the children 6-8 months had been appropriately introduced to solids, semi-solid and soft foods. This finding compares to those of in 06 kebeles in Jigjiga [38] where all the children of this age had been introduced to complementary feeding. At the age of 6 months, an infant's need for energy and nutrients starts to exceed what is provided by breast milk, thus complementary foods are necessary to meet energy and nutrient requirements, [39] and if complementary foods are not introduced when a child has completed 6 months of age, an infant's growth may falter [40].

Minimum dietary diversity: Dietary diversity has long been recognized as a key element of high quality diets and increasing the variety of foods consumed is thought to ensure adequate intake of essential nutrients and thus promote good health and nutrition $[41,42]$. Majority of the children had eaten food prepared from grains, tubers and roots like porridge, rice, bread, potatoes, yams and cassavas. This is comparable to the Ethiopia national figures as reported in Ethiopia Demographic Health Survey EDHS [20,21] and in Butembo-Democratic Republic of Congo. This can be related to the fact that being a low income community, the mothers would go for the cheaper foods which are usually grains/roots/tubers and their products and the fact that cereals form the staple food of any community. However, it is inferior that Porridge was not taken by almost all the children in this study since this is not a common complementary food. On the contrary, other studies have reported the high consumption of porridge $[43,44]$; a study in the rural western Kenya and [45] a study conducted in Utter Pradesh. Intakes of vitamin A rich fruits and vegetables were not adequate and decreased with age unlike for the Kenya national figures reported in Ethiopia Demographic Health Survey EDHS [20,21], where its intake increased with age. Vitamin A deficiency is among the nutritional deficiencies of greatest public health significance in the world today. Almost one third of children in developing countries are affected to some degree by vitamin A deficiency, which impairs their growth, development, vision and immune function, and in extreme cases leads to blindness and death [46]. Consumption of iron-rich foods (flesh meats) was low. Being a resource poor community, foods of animal origin are most likely out of the financial reach for the majority of the households. The consumption of proteins was highest from dairy products mostly milk, concurring with the study findings by [47] in Batudu District of Nepal and [48] in Gitega (Burundi) and Butembo (Democratic Republic of Congo).

Minimum meal frequency: In this study majority of the breastfed children attained minimum meal frequency unlike their counterparts, the non- breastfed children. This finding was in agreement with that of a study conducted in 08 kebeles [49,32]. Frequent meals are required to ensure the child receives enough energy [15]. In this study, less than a half of the mothers knew that children should be fed based on hunger cues which could be one of the influences on their feeding frequencies since majority of children may not necessarily show hunger cues.

\section{Mother's knowledge on complementary feeding}

Overall, mothers had average knowledge on complementary feeding practices. Knowledge on feeding practices of infants and young children is crucial for the health and nutrition wellbeing of a child [50]. Almost all the mothers were knowledgeable on the duration of exclusive breast feeding, correct timing of introduction of complementary foods and duration of breastfeeding. The knowledge level on breastfeeding and the recommended duration of breastfeeding in 04 kebeles was lower comparable to the findings of mothers in 06 kebeles [38]. UNICEF and WHO recommendations stipulate that children be exclusively breastfed fed for 6 months and that breast feeding continues for two years and beyond [39]. 
Mother knowledge on complementary food frequency was high that children should be fed based on hunger cues, ideal complementary feeding practices comprises of adequate meal frequency depending on whether the child is breasting [40]. Majority of the mothers were aware of the importance of enriching complementary foods and providing a diverse diet to their children. This is an important aspect in the infant and young children feeding practice as evidence in 04 kebeles. Mothers did not know the correct flours for making child porridge as indicated in the National strategy on infant and young child feeding 2007-2010 [51] that there is wide spread use of inappropriately constituted cereal and legume mixes in Ethiopia. Mothers went to the cereal shops and asked for porridge flours by mentioning the age of the child to the shopkeeper who is possibly not knowledgeable of the presence of phytates on the legumes (give me the porridge flour for an 8-month-old child). Still through the focus group discussions mothers reported that the most appropriate flours for making children's porridge flour was a mixture of maize, beans, millet, sorghum, finger millet, omena and cassava.

Flour mixtures of cereals and legumes are not appropriate for children; legumes contain phytates which bind iron [51]. Additionally, legumes take longer to cook than legumes and if not precooked can led to gastro-intestinal disturbances in children. Even though appetite may be reduced during illness, continued consumption of complementary foods is recommended to maintain nutrient intake and enhance recovery Brown KH, 2001. Many mothers indicated that sick and those recovering illness should be fed on dilute porridge and fruit juices only. This would be probably one of the causes of high malnutrition rates especially underweight and wasting. After illness, the child needs greater nutrient intake to make up for nutrient losses during the illness and allow for catchup growth. Extra food is needed until the child has regained any weight lost and is growing well again [40].

\section{Maternal hygiene practices}

Hygienic practices during food preparation and feeding is critical for prevention of gastrointestinal illness [40]. Mothers were knowledgeable on treating drinking water given to their children, but few of them thought washing of hands especially after returning from outside the house and after handling garbage was importance. This trend can be closely related to their low levels of education and may be more on the scarcity of water in urban areas.

\section{The nutritional status of the children}

Stunting rates of this study were lower than the national figures in children under five years. This was possibly because the study considered children aged 6-23 months old and also the fact the stunting rates increases with child age. Wasting was higher than the national figure. Underweight compared well with the national figure but was double the prevalence of underweight children in Somali region. However, underweight was similar to underweight rates in Central province as reported in EDHS [21]. The malnutrition rates were higher compared to 06 kebeles [38] and 08 kebeles [5255]. This study only examined the influence of maternal knowledge on complementary feeding practices hence nutritional status of children. Therefore, it is not possible to explain what factors could have contributed to the high prevalence of malnutrition in the study population.

\section{Conclusion}

The population was comprised of young mothers with low levels of education and low socio-economic status. Maternal knowledge on complementary feeding was on the whole appropriate; gaps were identified in appropriate feeding of the sick children and the appropriate use of mixed flours for making children's porridge. Complementary feeding practices were on the whole appropriate; in terms of introduction of solids, semi-solids and soft foods to children 6-8 months and minimum meal frequency especially for the breastfed children. Dietary diversity was low because of the limited socio-economic capability of the respondents to purchase a variety of foods. The prevalence of under-nutrition was high among the children and was influenced by maternal knowledge on complementary feeding practices and also the complementary feeding practices.

\section{Recommendations}

\section{Recommendations for policy and practice}

Messages on the promotion of appropriate IYCF practices by the Ministry of Health and other organizations dealing with child health should emphasize: appropriate feeding of the sick child and those recovering from illness; the importance of dietary diversity and frequency of feeding especially for non-breastfed children, to improve child's growth and health. The Ministry of Health and Organizations involved in child health issues should explore factors which influence mothers knowledge on complementary feeding hence child nutritional status with a view of taking appropriate action to improve complementary feeding practices. Positive cultural beliefs on complementary feeding practices should be encouraged and negative ones discouraged.

\section{Recommendations for further research}

This study was done in an urban poor-resource setting among mothers recruited from a health facility and therefore the findings may not be representative of mothers from such a setting. It is therefore recommended that a similar study in a community setting be conducted to verify the findings of this study. There is need to conduct a longitudinal study to establish the whole array of factors that influence complementary feeding practices and over a period of time since this study only focused on mothers" knowledge and socio-economic factors.

\section{Acknowledgement}

I would like to thank Jigjiga University college of Dry land agriculture, Department of food science and nutrition for giving us the opportunity to do this research, then I would like to thank all my food science and nutrition department staffs who encouraged and supported me with constructive advice and comment from beginning of title selection and problem identification to writing this research paper.

\section{References}

1. ENA (2011) Emergency Nutrition Assessment for Standardized Monitoring and Assessment of Relief and Transitions (ENA for SMART), Software User Manual. ACF Canada.

2. WHO (2005) Guiding Principles Feeding Non Breastfed Children 6-24 Months of Age. Geneva, Switzerland 1- 40.

3. Srivatsava N, Sandhu A (2007) Index for Measuring Child Feeding Practices. Indian J Pediatr 74(4): 363-368. 
4. Engle PL, Pelto G, Bentley B (2000) Care for Nutrition and Development. Journal of International Medical Association 98: 9

5. Sophie Naudeau, Rifat Hasan (2016) Early Childhood Development: A Review of the Global Evidence. World Bank Group.

6. Qiong Wu, Robert W Scherpbier, Michelle Helena Van Velthoven, Li Chen, Wei Wang et-al. (2014) Poor Infant and Young Child Feeding Practices and Sources of Caregivers' Feeding Knowledge in Rural Hebei Province, China: Findings from a Cross-Sectional Survey. BMJ Open 4(7): 1-8.

7. Shrimpton R, Victoria CG, de onis M, Lima RC, Blossner M, et al. (2001) Worldwide Timing of Growth Faltering Implication for Nutritional Intervention. Pediatrics 75: 107.

8. LC Fernald, LM Neufeld (2007) Overweight with Concurrent Stunting in Very Young Children from Rural Mexico: Prevalence and Associated Factors. Eur J Clin Nutr 61(5): 623-632.

9. Black RE, Allen LH, Bhutta ZA, Caulfield LE, de Onis M, et al. (2008) Maternal and Child Undernutrition: Global and Regional Exposures And health Consequences. Lancet 371(9608): 243-260.

10. Amanda Zongrone, Kate Winskell, Purnima Menon (2012) Infant and Young Child Feeding Practices and Child Undernutrition in Bangladesh: Insights from Nationally Representative Data. Public Health Nutr 15(9): 1697-1704.

11. WHO (2006) Child Growth Standards. Geneva, Switzerland.

12. Pelto GH, Levi E, Thairu L (2003) Improving Feeding Practices, Current Patterns; Common Constrains and the Design of Intervention. Food Nutr Bull 24(1): 45-82.

13. Henry Wamani, Anne Nordrehaug Åstrøm, Stefan Peterson, James K Tumwine, Thorkild Tylleskär, et al. (2007) Boys Are More Stunted than Girls in Sub-Saharan Africa: A Meta-Analysis of 16 Demographic and Health Surveys. BMC Pediatr 7: 17

14. Chessa K Lutter, Juan A Rivera (2003) Nutritional Status of Infants and Young Children and Characteristics of Their Diets. J Nutr 133(9): 2941S-2949S.

15. PAHO/WHO (2003) Guiding Principles for Complementary Feeding of the Breast-Fed Child. Washington DC, USA.

16. Barry M Popkin, Linda S Adair, Shu Wen Ng (2012) NOW AND THEN: The Global Nutrition Transition: The Pandemic of Obesity in Developing Countries. Nutr Rev 70(1): 3-21.

17. ACC/SCN, (2000) The Fourth Report on World Nutrition Situation. Geneva, Switzerland.

18. WHO (2000) The Global Database on Child Growth and Malnutrition Forecast of Trend WHO. Geneva, Switzerland.

19. UNICEF (2007) Status of Child Survival and Development in Eastern and Southern Africa. UNICEF, Kenya.

20. KNBS (2010) Kenya demographic and health survey 2008-09. kenya demographic and health survey 2008-09. KENYA: Kenya National Bureau of Statistics Nairobi, Kenya.

21. KNBS, ICF Macro (2010) Kenya Demographic Survey 2008-2009. Calverton, Maryland: KNBS and ICF Macro.

22. UNDP (2008) Capacity Assessment Methodology. New York, NY 10017 USA: UNDP.

23. WHO (2010) Indicators for Assessing Infant and Young Child Feeding Practices Part 2: Measurement. World Health Organization 1-81.

24. Sellen DW (2001) Weaning, Complementary Feeding and Maternal Decision Making in a Rural East African Pastoral Population. J Hum Lact 17(3): 233-244.

25. Central Statistical Authority and ORC Macro (2012) Ethiopia Demographic and Health Survey 2011. Addis Ababa, Ethiopia and Calverton, Maryland.

26. ESRS (2011) Annual Report of Jigjiga Council Health Office. Unpublished.

27. Yamane Taro (1967) Statistics, an Introductory Analysis. 2nd Edition. New York, Haper and row (1-919).
29. WHO (2007) Indicators for Assessing Infant and Young Child Feeding Practices: Conclusions of a Consensus Meeting Held 6-8 November 2007 in Washington D.C, USA 1-19.

30. PAHO/WHO (2003) Guiding Principles for Complementary Feeding of the Breast-Fed Child. Washington DC, USA.

31. ENA (2011) Emergency Nutrition Assessment for Standardized Monitoring and Assessment of Relief and Transitions (ENA for SMART), Software User Manual. ACF Canada.

32. WHO (2006) Child Growth Standards. Geneva, Switzerland.

33. Kimani Murage EW, Madise NJ, Fotso JC, Kyobutungi C, Mutua MK, et al. (2011) Patterns and Determinants of Breastfeeding and Complementary Feeding Practices in Urban Informal Settlements, Nairobi Kenya. BMC Public Health 11: 396.

34. Ochola SA (2008) Evaluation of Two Counseling Strategies Promoting Exclusive Breastfeeding among HIV-Negative Mothers in Kibera Slum, Nairobi, Kenya: A Randomized Controlled Trial. Thesis (PhD (Interdisciplinary Health Sciences. Human Nutrition))--Stellenbosch University.

35. Levin, Margaret Armar Klemesu, Marie T Ruel, Daniel G Maxwell, Carol E, et al. (2000) Poor Maternal Schooling Is the Main Constraint to Good Child Care Practices in Accra. Journal of Nutrition 130: 1597-1607.

36. Qiong Wu, Robert W Scherpbier, Michelle Helena Van Velthoven, Li Chen, Wei Wang, et al. (2014) Poor Infant and Young Child Feeding Practices and Sources of Caregivers' Feeding Knowledge in Rural Hebei Province, China: Findings from a Cross-Sectional Survey. BMJ Open 4(7): 1-8.

37. Mukuria GA, Kothari M, Noureddine A (2006) Infant and Young Child Feeding Update ORC Macro Calverton. Maryland, USA 3-25.

38. Kipruto KJ (2013) Complementary Feeding and Nutritional Status of Children Aged 6-23 Months in Korogocho Slum. M.Sc. Thesis, Kenyatta University.

39. WHO (2006) Infant and Young Child Feeding Counselling: An Integrated Course, Director's Guide. Geneva, Switzerland: World Health Organization.

40. WHO (2001) Guiding Principles of Complementary Feeding. Geneva, Switzerland.

41. Chessa K Lutter, Juan A Rivera (2003) Nutritional Status of Infants and Young Children and Characteristics of Their Diets. J Nutr 133(9): 2941S-2949S

42. Lutter CK, Rivera JA (2003) Nutritional Status of Infants and Young Children and Characteristics of Their Diets. J Nutr 133(9): 29415-29495.

43. Mbagaya MG (2009) Child Feeding Practices in Rural Western Kenya Community. Afr J Prim Health Care Fam Med 1(1): 15-19.

44. KM Anigo, DA Ameh, S Ibrahim, SS Danbauchi (2010) Nutrient Composition of Complementary Food Gruels Formulated from Malted Cereals, Soybeans and Groundnut for Use in North-Western Nigeria. African Journal of Food Science 4(3): 65-72.

45. Kumudha A, Khan ME, Avishek H (2010) Complementary Feeding in Rural Utter Pradesh. The Journal of Family Welfare, Special Issue 56: $1-56$.

46. Gretel H Pelto, Margaret Armar Klemesu (2011) Balancing Nurturance, Cost and Time: Complementary Feeding in Accra, Ghana. Matern Child Nutr 7(3): 66-81.

47. Hellen keller international Nepal (2010) Breastfeeding and Complementary Feeding Practices Are Less than Adequate among Mothers of Children 12-23 Months in the Baitadi District of Nepal. 3rd issue. Nepal nutrition and food security bulletin.

48. Ekesa B N, Blomme G, Garming H (2011) Dietary Diversity and Nutritional Status of Pre-School Children from Musa-Dependent Households in Gitega (Burundi) and Butembo (Democratic Republic of Congo). African Journal of Food, Agriculture, Nutrition and Development 11: 4.

49. Adere JW (2006) Feeding Practices and Nutritional Status of Children 6-36 Months in Muslim and Christian Households: A Human Rights Perspective (A Case Study of Kibera in Nairobi). University of Nairobi.

28. Seca (2014) Medical Measuring Systems and Scales since 1840. 
50. Bineti S Vitta, Margaret Benjamin, Alissa M Pries, Mary Champeny, Elizabeth Zehner et-al. (2016) Infant and Young Child Feeding Practices among Children under 2years of Age and Maternal Exposure to Infant and Young Child Feeding Messages and Promotions in Dar Es Salaam, Tanzania. Matern Child Nutr 12(2): 77-90.

51. MOPHS (2011) Nutrition Survey, Marsabit District Kenya. Food for the Hungry, Kenya. UNICEF.

52. Kariuki FN, Monari JM, Kibui MM, Mwirichia MA, Zani KK et-al. (2002) Prevalence and Risk Factors of Malnutrition of Children 6-23 Months in Kibera Nairobi, Kenya. Journal of National Institute of Public Health 51(1): 45-47.
53. Murage KE, Madise NJ, Fotso JC, Kyobutungi C, Mutua MK, et al. (2011) Patterns and Determinants of Breastfeeding Practices and Complementary Feeding in Urban Informal Settlement, Nairobi Kenya. BMC Public Health 11: 396.

54. Pelto GH, Levi E, Thairu L (2003) Improving Feeding Practices, Current Patterns; Common Constrains and the Design of Intervention. Food Nutr Bull 24(1): 45-82.

55. WHO (2003) Guiding Principles for Complementary Feeding of the Breast-Fed Child. Washington DC, USA. 